\title{
Screening for genomic rearrangements and methylation abnormalities of the $15 q 11-q 13$ region in autism spectrum disorders
}

Christel Depienne, ${ }^{1,2,3}$ Daniel Moreno-De-Luca, ${ }^{4,3}$ Delphine Heron, ${ }^{2}$ Delphine Bouteiller, ${ }^{1}$ Aurélie Gennetier, ${ }^{4,3}$ Richard Delorme, ${ }^{5}$ Pauline Chaste, ${ }^{5}$ Jean-Pierre Siffroi, ${ }^{6}$ Sandra Chantot-Bastaraud, ${ }^{6}$ Baya Benyahia, ${ }^{2}$ Oriane Trouillard, ${ }^{2}$ Gudrun Nygren, ${ }^{7}$ Svenny Kopp, ${ }^{7}$ Maria Johansson, ${ }^{7}$ Maria Rastam, ${ }^{7}$ Lydie Burglen, ${ }^{6}$ Eric Leguern, ${ }^{1,2,3}$ Alain Verloes, ${ }^{8}$ Marion Leboyer, ${ }^{9,10,11}$ Alexis Brice, ${ }^{1,2,3}$ Christopher Gillberg, ${ }^{7,12}$ Catalina Betancur ${ }^{4,3}$

${ }^{1}$ INSERM U679, Groupe Hospitalier Pitié-Salpêtrière, Paris, France

${ }^{2}$ AP-HP, Département de Génétique, Cytogénétique et Embryologie, Fédération de Génétique, Groupe Hospitalier Pitié-Salpêtrière, Paris, France

${ }^{3}$ Université Pierre et Marie Curie, Paris, France

${ }^{4}$ INSERM U513, Paris, France

${ }^{5}$ AP-HP, Service de Psychopathologie de l'Enfant et de l'Adolescent, Hôpital Robert Debré, Paris, France

${ }^{6}$ AP-HP, Service de Génétique et d'Embryologie Médicales, Hôpital Trousseau, Paris, France

${ }^{7}$ Goteborg University, Department of Child and Adolescent Psychiatry, Goteborg, Sweden

${ }^{8}$ AP-HP, Département de Génétique, Hôpital Robert Debré, Paris, France

${ }^{9}$ AP-HP, Department of Psychiatry, Groupe Hospitalier Henri Mondor et Albert Chenevier, Créteil, France

${ }^{10}$ INSERM U841, Institut Mondor de Recherche Biomedicale, Psychiatric Genetics, Créteil, France

${ }^{11}$ Université Paris 12, Faculté de Médecine, Créteil, France

${ }^{12}$ Institute of Child Health, London, United Kingdom

Correspondence to: C. Betancur, INSERM U513, Université Pierre et Marie Curie, 9 quai Saint Bernard, 75252 Paris Cedex 05, France. Tel: +33 14442761 19; fax: +33 1442760 69; e-mail: Catalina.Betancur@inserm.fr

Key words: autism, chromosome 15, deletion, duplication, Angelman syndrome, MLPA 


\section{Abstract}

Background: Maternally-derived duplications of the 15q11-q13 region are the most frequently reported chromosomal aberrations in autism spectrum disorders (ASD). Prader-Willi and Angelman syndromes, caused by 15q11-q13 deletions or abnormal methylation of imprinted genes, are also associated with ASD. However, the prevalence of these disorders in ASD is unknown. The aim of this study was to assess the frequency of 15q11-q13 rearrangements in a large sample of patients ascertained for ASD.

Methods: A total of 522 patients belonging to 430 families were screened for deletions, duplications and methylation abnormalities involving 15q11-q13 using multiplex ligation-dependent probe amplification (MLPA).

Results: We identified four patients with 15q11-q13 abnormalities: a supernumerary chromosome 15, a paternal interstitial duplication, and two subjects with Angelman syndrome, one with a maternal deletion and the other with a paternal uniparental disomy.

Conclusions: Our results show that abnormalities of the 15q11-q13 region are a significant cause of ASD, accounting for approximately $1 \%$ of cases. Maternal interstitial 15q11-q13 duplications, previously reported to be present in $1 \%$ of patients with ASD, were not detected in our sample. Although paternal duplications of chromosome 15 remain phenotypically silent in the majority of patients, they can give rise to developmental delay and ASD in some subjects, suggesting that paternally-expressed genes in this region can contribute to $\mathrm{ASD}$, albeit with reduced penetrance compared to maternal duplications. These findings indicate that patients with ASD should be routinely screened for $15 \mathrm{q}$ genomic imbalances and methylation abnormalities and that MLPA is a reliable, rapid and cost-effective method to perform this screening. 


\section{Introduction}

Autism is a neurodevelopmental disorder characterized by impaired social interaction and communication, and a restricted range of interests and activities, with onset during the first three years of life. Autism spectrum disorders (ASDs), which include autism, pervasive developmental disorder not otherwise specified (PDD-NOS) and Asperger syndrome, have a typical male preponderance and their estimated prevalence is 6/1000 (1). ASDs are etiologically heterogeneous, with an underlying genetic disorder identified in 10\%-25\% of cases. Monogenic disorders such as fragile X syndrome, tuberous sclerosis, and Rett syndrome are found in a small percentage of patients; in addition, rare mutations in other genes (e.g., NLGN3, NLGN4X, PTEN, SHANK3) have been reported in a small number of individuals (2). Cytogenetically visible chromosomal aberrations are identified in 3\%-6\% of affected individuals $(3,4)$, while recent higher-resolution whole-genome analyses using array-based technologies have revealed genomic imbalances in at least $10 \%$ of cases (5-7).

Duplications of the 15q11-q13 region are the most frequently reported chromosomal aberration in individuals with ASDs (8). This region includes the Prader-Willi syndrome/Angelman syndrome (PWS/AS) critical region, which is subject to genomic imprinting. Most duplications of this interval are caused by supernumerary chromosomes formed by the inverted duplication of proximal $15 \mathrm{q}$, known as isodicentric chromosome 15 [idic(15)] (9-13). Interstitial duplications of this region are less frequent (14), but many cases have been reported in association with autism $(10,13,15-17)$. The majority of cases are associated with maternally-derived duplications, whereas paternal inheritance usually leads to normal phenotypes $(10,15,16,18)$.

Deletions or methylation abnormalities of chromosome 15 result in either Prader-Willi syndrome or Angelman syndrome, depending on whether they arise on the paternal or maternal chromosome. Both syndromes have been described in patients with ASD or autistic behavior, and recent studies estimate that over half of the patients with Angelman syndrome have ASD (19-21).

The genomic instability of proximal chromosome 15 is mediated by low-copy repeats, resulting in five recurrent breakpoints (BP) involved in deletions, duplications and idic(15) (22). The deletions involve either the proximal BP1 or BP2 and share the same distal breakpoint (BP3), whereas the duplications can extend more distally to BP4 or BP5 (Fig. 1). The critical region involved in PWS/AS and the 15q11-q13 duplication syndrome lies between BP2 and BP3. Nonallelic homologous recombination between flanking low-copy repeats is also involved in other microdeletion/microduplication syndromes associated with mental retardation and ASDs, including $17 \mathrm{p} 11.2,22 \mathrm{q} 11.2$ and $7 \mathrm{q} 11.23(23)$.

Although the frequency of $15 \mathrm{q} 11-\mathrm{q} 13$ duplications in autism is widely assumed to be $1 \%-3 \%$, this estimate is based on two small series of patients. In a study of 140 subjects with autism, two were found with a maternal interstitial duplication of 15q11-q13 (24). Schroer et al. studied 100 patients with autism and identified two idic(15), one maternally-derived interstitial duplication and one maternal deletion (10). The small numbers of patients studied makes it difficult to draw conclusions on the real 
contribution of such duplications to ASD. The prevalence of proximal 15q deletions in ASDs is also unknown. Recent genome-wide studies of copy number variants in large ASD samples included an unknown proportion of patients who had been previously screened for chromosomal abnormalities and $15 \mathrm{q} 11-\mathrm{q} 13$ rearrangements (and excluded if positive), thus precluding the estimation of prevalence $(5,6)$.

The aim of this study was to assess the frequency of 15q11-q13 abnormalities in 522 individuals with ASDs. We screened the PWS/AS region for gene dosage alterations using multiplex ligationdependent probe amplification (MLPA) and quantitative microsatellite analysis. In addition, we searched for methylation abnormalities of chromosome 15, including uniparental disomies and imprinting center defects, using methylation-sensitive MLPA (25). Epigenetic defects have long been suspected in autism $(26,27)$, but no systematic screening of methylation abnormalities of chromosome 15 had been performed.

\section{Methods and Materials}

\section{Patients}

A total of 522 patients with ASD belonging to 430 families were studied. Subjects were recruited by the Paris Autism Research International Sibpair (PARIS) study at specialized clinical centers in Europe and the United States. The patients included 393 males and 129 females (ratio 3:1), with a mean age at the last evaluation of $11 \pm 7.5$ years (range 2.5-43); 187 belonged to 95 multiplex families (with two or more affected siblings) and 335 were sporadic cases. All patients were evaluated by psychiatrists or child neurologists and diagnosed based on clinical evaluation and DSM-IV criteria. Patients were assessed with the Autism Diagnostic Interview-Revised (ADI-R) (28) and the Asperger Syndrome Diagnostic Interview (29). Four-hundred seventy-two individuals met criteria for autism, 26 for Asperger syndrome and 24 for PDD-NOS. Three-hundred fifty-six patients (68\%) had mental retardation, $261(50 \%)$ had very limited or no language, and $66(13 \%)$ had a history of epilepsy. Most patients were Caucasian (89\%). Laboratory tests included karyotype, fragile $\mathrm{X}$ and metabolic screening; brain imaging and EEG were performed when possible. Patients with known genetic disorders were excluded. Chromosome analysis identified one female harboring a supernumerary isodicentric derivative chromosome 15; we report here the cytogenetic, molecular and phenotypic characterization of this patient. No other patients had been excluded from the sample prior to this study because of cytogenetic abnormalities of chromosome 15q11-q13. The study was approved by the research ethics boards of the collaborating institutions. Informed consent was obtained from all families participating in the study.

\section{Multiplex ligation-dependent probe amplification (MLPA)}

Patients were screened for rearrangements involving the 15q11-q13 region using the ME028 PWS/AS and/or the P064 MR1 MLPA kits ( $\mathrm{n}=351$ and 522, respectively) (MRC-Holland). The ME028 kit contains 25 probes specific for sequences in or near the PWS/AS critical region, as well as 5 probes to assess methylation status (25). The P064 kit contains 5 probes in the PWS/AS region (one probe in 
$M K R N 3, N D N$, and GABRB3, and two in $U B E 3 A$ ). MLPA data were analyzed using GeneMarker 1.70 software (SoftGenetics). After population normalization, the peak height from each sample was compared to a synthetic control, which represents the median of all normal samples in each experiment. Peak heights below 0.75 were considered as deletions and values above 1.3 as duplications. Cases with apparent deletions or duplications were confirmed with quantitative PCR (qPCR) and fluorescent in situ hybridization (FISH). Apparent deletions of a single probe were sequenced to rule out single-base changes within the probe-binding region. For further details see Supplement 1.

\section{Quantitative microsatellite analysis}

Five microsatellite markers in the 15q11-q13 region (D15S11, D15S817, D15S1513, D15S1019 and D15S815) were used to assess DNA copy number and follow the transmission of the alleles (Fig. 1). PCR conditions (in particular the number of PCR cycles) were set up so as to perform allele dosage. PCR products were quantified on an ABI 3730 sequencer (Applied Biosystems).

\section{Results}

Five quantitative assays using microsatellites were used to screen the 15q11-q13 region in 217 patients. However, analysis of the markers D15S11 and D15S817 revealed three alleles in 10\% of patients, a proportion comparable to that in a control population, indicating that this region is duplicated in healthy individuals. We therefore decided to screen all patients using MLPA.

Overall, we identified four patients with 15q11-q13 abnormalities considered to be pathogenic: an idic(15), an interstitial duplication, a deletion and an uniparental disomy. Their clinical features are summarized in Table 1 and are described in more detail in Supplement 1.

\section{Supernumerary isodicentric chromosome 15}

Patient 1 had an idic(15) revealed by the karyotype and confirmed by FISH, described as 47,XX,+mar.ish der(15)(D15Z1++, SNRPN++, UBE3A++) (Fig. 2A). Microsatellite analysis of the patient and her parents showed that she had a de novo copy number gain of D15S11, D15S817 and D15S815 (Fig. 2B). Methylation-sensitive MLPA revealed that the idic(15) was maternally-derived, as indicated by the increased dosage of the methylated probes in SNRPN and NDN (Fig. 3). MLPA confirmed that the idic(15) involved all the probes in the 15q11-q13 region (between BP1 and BP3) but did not affect two genes located distally, at 15q26, BLM and IGF1R (Fig. 2C). Further analysis of the 15q11-q13 interval with 15 microsatellites showed six triallelic markers, with one allele of paternal origin and two of maternal origin (Fig. 2D). One informative microsatellite between BP4 and BP5, D15S1031, had a single maternal allele, suggesting the breakpoint lies proximal to this marker (Fig. 2D). Detailed investigation of the distal breakpoint with qPCR showed increased dosage of MTMR10, TRPM1 and $K L F 13$, located between BP4 and BP5, but two distal genes in the same interval, OTUD7A and CHRNA7, showed a normal copy number (Fig. 2E). These findings suggest that the distal breakpoint of the idic(15) lies between BP4 and BP5, in agreement with the microsatellite results. The KLF13 probe 
showed an increase in dosage to the hexasomy range, suggesting a complex rearrangement at the site of the breakpoint. We could not differentiate between one or two breakpoints, because of the inability to estimate the precise copy number of individual probes on the basis of qPCR (Fig. 2E).

\section{Interstitial 15q11-q13 duplication}

Patient 2 had three alleles for both D15S11 and D15S817. He was homozygous for D15S1513 and D15S1019, which were therefore uninformative, and heterozygous without imbalance for D15S815, located between BP3 and BP4 (not shown). MLPA confirmed the presence of a $\sim 4.6 \mathrm{Mb}$ duplication between BP2 and BP3, corresponding to the critical region deleted in PWS/AS (Fig. 4). Methylationsensitive MLPA showed normal dosage of the methylated maternal probes in SNRPN and NDN, indicating that the duplication was paternally derived (Fig. 3). MLPA of the parents showed that the duplication was inherited from the unaffected father (Fig. 4). Methylation analysis of the father showed a paternal origin of the duplication (not shown), but no DNA was available from the grandfather to determine if the duplication was inherited or had arisen de novo. FISH using the UBE3A probe confirmed the presence of an increased signal in Patient 2 (not shown).

\section{Angelman syndrome: deletion and uniparental disomy}

Patients 3 and 4 had only one allele for three markers located in the PWS/AS region (D15S11, D15S817 and D15S1513), suggesting that they could be either homozygous or deleted in this region (Fig. 5A). Examination of the parents' haplotypes showed that both patients had only one allele from the father and none from the mother (Fig. 5A). MLPA confirmed that Patient 3 had a maternal class I deletion extending $\sim 5.6 \mathrm{Mb}$ from $\mathrm{BP} 1$ to $\mathrm{BP} 3$ that arose de novo (Fig. 3, 5C). FISH with probe D15S10 confirmed the deletion (not shown). In Patient 4, MLPA showed a normal copy number of the 15q11-q13 region (Fig. 5C) but methylation-sensitive MLPA revealed a complete absence of maternal methylated DNA sequences, indicating a paternal uniparental disomy (Fig. 3). FISH showed normal hybridization of probes SNRPN and D15S10 (not shown), consistent with the diagnosis of uniparental disomy.

\section{Abnormal copy number of the BP1-BP2 region}

MLPA also detected three patients with a deletion (Patients 5,6 and 7) and two with a duplication (Patients 8 and 9) of the BP1-BP2 interval, which spans $254 \mathrm{~kb}$ and encompasses four genes, TUBGCP5, CYFIP1, NIPA1, and NIPA2 (Fig. 1). All the rearrangements were inherited from parents who were unaffected or had unrelated psychiatric disorders (Table 1).

The cytoplasmic FMR1 interacting protein 1 (CYFIP1) interacts with FMRP, encoded by the fragile $\mathrm{X}$ mental retardation 1 (FMR1) gene. Since fragile X syndrome is often associated with autism, CYFIP1 constitutes a candidate gene for autism. In order to test the possibility that point mutations in this gene, either inherited from the other parent or de novo, could lead to autism in association with the BP1-BP2 imbalance, we sequenced the whole coding region of CYFIP1 in the five probands with abnormal dosage of this region. In Patients 5 and 8 we extended the search of point mutations to the coding regions of 
NIPA1, NIPA2 and TUBGCP5, as well as those of FMR1, FXR1 and FXR2, which encode proteins of the FMRP complex. No mutations were identified in any of the genes screened.

\section{Other deletions or sequence variants considered non pathogenic}

We identified one patient with a paternally-inherited deletion of exon 1 in one of the transcript variants of the $U B E 3 A$ gene. Because the deleted exon is noncoding and $U B E 3 A$ is maternally expressed, this genomic imbalance is unlikely to have clinical consequences. In another patient, MLPA showed an apparent deletion of one probe in the $S N R P N$ promoter/exon1 region, due to a maternally-inherited nucleotide change previously reported as a rare neutral variant (see Supplement 1 for further details on these two patients).

\section{Methylation abnormalities}

Aside from the uniparental disomy identified in Patient 4, no other methylation abnormalities were observed in 331 patients screened with methylation-sensitive MLPA. In the remaining subjects, uniparental disomy was ruled out with microsatellite analysis.

\section{Discussion}

In this study, we found a pathogenic rearrangement of the 15q11-q13 region in 4 out of 430 families. Thus, proximal $15 \mathrm{q}$ abnormalities, including deletions, supernumerary isodicentric chromosomes and interstitial duplications, are found in about $1 \%$ of patients with ASD, representing one of the most common genetic causes of ASD, together with fragile X syndrome.

\section{Supernumerary chromosome 15 and ASD}

Supernumerary marker chromosomes are a relatively common cytogenetic finding, with an estimated incidence of 0.8/1000 prenatal diagnoses; those derived from chromosome 15 account for about half of all marker chromosomes (30). The frequency is higher in children with developmental delay, with 10 idic(15) identified in 2000 such cases in one study (11). Idic(15) that do not include the PWS/AS critical region have no clinical effect (31), whereas those including the PWS/AS region lead to a neurobehavioral phenotype including autism or autistic-like behavior, cognitive deficits, hypotonia, mild dysmorphic features, and seizures (32). There have been numerous reports of idic(15) associated with autism (9-13). As in Patient 1, the vast majority of idic(15) that encompass the PWS/AS locus are maternally derived and arise de novo (33). Almost two-thirds extend beyond BP3 and the majority are asymmetrical, with two distinct breakpoints, at BP4 and BP5 $(14,33)$. Analysis of the number of copies across the 15q11-q13 region in Patient 1 with qPCR and microsatellites predicted an atypical distal breakpoint between BP4 and BP5. A similar breakpoint was reported in a patient with an idic(15), between D15S1013 and D1S1031 (33).

Although genotype/phenotype correlation studies show that the segmental tetrasomy of idic(15) is associated with a more severe phenotype in terms of developmental outcome compared to interstitial triplications or duplications, indicating a dosage effect, no clear correlation has been observed between 
gene dosage and autism phenotype (34). Furthermore, no consistent relationship has been observed between rearrangement size and clinical severity $(11,34)$.

\section{Interstitial duplications and ASD}

At least 33 cases of interstitial duplications of the 15q11-q13 region have been reported in association with ASDs, according to the Autism Chromosome Rearrangement Database (http://projects.tcag.ca/autism/). Interstitial duplications of proximal 15q that do not include the PWS/AS critical region have no clinical effect, are usually familial and may be considered normal variants (18). Patients with interstitial duplications of the PWS/AS locus have an abnormal phenotype that includes developmental delay, particularly affecting speech and language, varying degrees of mental retardation, autism or autistic features, motor coordination difficulties, and mild or no dysmorphic features (16). The phenotype is highly variable, even among members of the same family carrying identical rearrangements (16) and can in some cases manifest as developmental language disorder and dyspraxia, without autism (35). The clinical findings in Patient 2 are similar to those described in patients with maternal 15q11-q13 duplications, although he lacks the hypotonia, motor coordination problems and joint laxity observed in other cases $(16,17)$.

The frequency of $15 \mathrm{q} 11-\mathrm{q} 13$ interstitial duplications is estimated at 1:600 individuals referred with developmental delay (36). Although previous studies in small samples of patients had suggested a frequency of $1 \%$ for maternally-derived interstitial duplications in autism $(10,24)$, we did not detect any such cases in our sample but found one patient harboring a paternal 15q11-q13 duplication. In agreement with our findings, Bolton et al. screened 181 patients with autism and found only one interstitial duplication of paternal origin (37). Similarly, Thomas et al. studied 327 samples referred for a suspected ASD as well as 87 patients with confirmed autistic disorder and found no 15q duplications (36). More recently, a genome-wide microarray study of 427 subjects with ASD identified two maternally-derived 15q11-q13 duplications (7). Collectively, these results suggest that maternal interstitial duplications are less frequent than previously assumed, with an estimated $\sim 0.3 \%$ frequency $(4 / 1369)$ in subjects with ASD. Based on the same studies, the estimated frequency of idic(15) is $\sim 0.2 \%(3 / 1369)$ and that of paternal duplications $\sim 0.1 \%(2 / 1369)$. Note however, that the frequency of $\operatorname{idic}(15)$ may be underestimated because previous studies included an unknown proportion of subjects that had been screened for cytogenetic abnormalities prior to inclusion. It also should be noted that none of these studies were based on epidemiological samples and the possibility of ascertainment biases cannot be excluded.

\section{Maternal versus paternal duplications}

Interstitial duplications of 15q11-q13 of maternal origin are associated with developmental delay and/or autistic behavior, whereas paternally-derived duplications usually lead to a normal phenotype $(10,15,16$, 18). However, as shown in Table 2, there have been at least six reports of paternal duplications encompassing the PWS/AS region associated with an abnormal phenotype, including mental retardation, 
delayed or absent speech, and ASD or autistic behavior (37-41). In addition, two patients with an interstitial 15q11-q13 triplication of paternal origin have been reported $(42,43)$. Together with the patient with the paternal duplication described here, these findings suggest that paternally-derived duplications may lead to phenotypic effects, including autism. Thus, there may be other genetic and/or environmental/epigenetic factors operating to modify the penetrance and expressivity of paternal duplications. Similar as yet unknown factors could come into play to modify the phenotypic expression of maternal 15q11-q13 duplications, which are also associated with a wide range of developmental problems and show marked clinical variability among members of the same family, including individuals who appear unaffected (16).

It is interesting to note that several of the patients with paternally-inherited duplications or triplications described previously had Prader-Willi syndrome-like features (Table 2) (38, 40, 43), suggesting a role of paternally-expressed genes mapping within the PWS/AS region (e.g., MKRN3, $M A G E L 2, N D N$, and $S N R P N-S N U R F)$ in the phenotypic manifestations. Several recent studies have shown that ASD is more prevalent in Prader-Willi syndrome patients than was previously thought (44), in agreement with a contribution of paternally-expressed genes to the ASD phenotype. Further research is needed to examine the effect of parental origin on phenotypic outcomes of 15q11-q13 duplications and their contribution to ASD. In particular, studies of gene expression in tissues from patients with paternal duplications may improve our understanding of the effect of these rearrangements on phenotype.

\section{Angelman syndrome and ASD}

The prevalence of Angelman syndrome is estimated at 1/12,000 (45). Angelman syndrome is characterized by severe mental retardation, profound speech impairment, ataxia, and typical behavior including happy disposition with frequent laughter/smiling and hand-flapping. Seizures, microcephaly and distinctive physical traits (large open mouth, widely-spaced teeth, prognathism) are also common (46). It is caused by deficiency of the maternally-inherited $U B E 3 A$ gene, resulting from deletion of the maternal 15q11.2-q13 region (70\%), paternal uniparental disomy (2\%), UBE3A mutations (10\%), or imprinting defects (5\%), with no molecular abnormality identified in the remaining patients (13).

The association between Angelman and autism has been known for more than a decade (45). According to recent data, 62\% (38/61, range 50\%-81\%) of subjects with Angelman syndrome meet criteria for autism or ASD (19-21), suggesting that ASD may be part of the behavioral phenotype of Angelman syndrome. Although the diagnosis of ASD in Angelman syndrome is complicated by the severe intellectual disability usually observed in these patients, there is clear evidence for ASD in a subgroup of Angelman patients who exhibit social and communication deficits that are disproportionate to their overall cognitive function. There is little information about the prevalence of Angelman syndrome in ASD. Schroer et al. found one maternal 15q11-q13 deletion among 100 patients with autism (10). In this study, we identified two subjects with Angelman syndrome, one with a maternal deletion and the second with a uniparental disomy, for a $\sim 0.5 \%$ frequency. 
Because certain features of autism overlap with those seen in Angelman syndrome, including severe mental retardation, absence of speech or very limited language, epilepsy and/or abnormal EEG, and stereotyped behaviors, the diagnosis of Angelman syndrome may be overlooked in patients with ASD, as happened with our two patients. Although neither patient exhibited the classical phenotype, their clinical presentation is within the normal range of phenotypic variability observed in Angelman syndrome. In common with the majority of patients with Angelman, they exhibited severe cognitive impairment and limited or absent language, but had no ataxia or microcephaly, and seizures and unprovoked laughter (during infancy only) were observed only in one.

\section{BP1-BP2 microdeletions/microduplications}

We identified three deletions and two duplications of the region between BP1 and BP2, all inherited from unaffected parents. A BP1-BP2 deletion was reported recently in a boy with mental retardation, speech delay and neurological deficits, but the interpretation was complicated by the presence of the same deletion in the father, who also showed cognitive impairment (47). Copy number gains and losses of this region have also been identified in genome-wide array analyses of control individuals (Database of Genomic Variants, http://projects.tcag.ca/variation/), with a population frequency estimated at 1\% (48), suggesting that this may be a copy number polymorphism. In agreement with this interpretation, individuals carrying small idic(15) with extra copies of the four genes included in the BP1-BP2 interval but that do not carry extra genomic material distal to BP2 are phenotypically normal (31), suggesting that these genes do not exert clinically significant dosage effects.

Nevertheless, it is interesting to note that NIPA1, NIPA2, CYFIP1 and TUBGCP5 have been suggested to modulate the PWS/AS phenotype. Angelman patients with class I deletions (including the BP1-BP2 interval) are more likely to meet criteria for autism and lack vocalizations compared with patients having smaller class II deletions (20). Similarly, in Prader-Willi syndrome, class I deletions are associated with more obsessive-compulsive behaviors and lower intellectual ability (49), and mRNA levels of these four genes are positively correlated with better behavioral outcomes (50). More recently, BP1-BP2 deletions were shown to be significantly associated with schizophrenia (51), suggesting that these variants may increase risk for various neuropsychiatric phenotypes, albeit with low penetrance and/or variable expressivity.

One of the genes situated in this interval, CYFIP1, is particularly interesting in the context of ASD. CYFIP1 interacts with fragile X mental retardation protein (FMRP) as well as with the Rho GTPase Rac1, which plays a role in the regulation of axonal migration and dendritic spine morphology. CYFIP1 has been proposed as a potential molecular link between fragile $\mathrm{X}$ syndrome and 15q11-13 duplication, since both disorders result in excess free CYFIP1 (52). In order to test the possibility that the BP1-BP2 deletion unmasked a recessive mutation on the other chromosome we sequenced CYFIP1, as well as NIPA1, NIPA2, TUBGCP5, and genes encoding fragile X-related proteins (FMR1, FXR1 and FXR2), in patients carrying BP1-BP2 deletions, identifying no mutations. Clearly, more research is required to 
determine the phenotype correlations of BP1-BP2 deletions and duplications and the role of NIPA1, NIPA2, CYFIP1 and TUBGCP5, if any, in neurodevelopmental disorders.

\section{Conclusion}

The present findings confirm that genetic abnormalities of the 15q11-q13 region are an important cause of ASD, accounting for approximately $1 \%$ of cases. Our results suggest that patients with ASD, particularly those with mental retardation, should be systematically screened for duplications, deletions and methylation abnormalities of the PWS/AS region. Routine chromosomal analysis, currently recommended in the etiological evaluation of individuals with autism, would miss many of the deletions and duplications in the 15q11-q13 region, as well as cases resulting from uniparental disomy. Traditional cytogenetic tests such as FISH are expensive and would miss some duplications and all cases of uniparental disomy. Furthermore, array-based methods are also expensive and currently are not in wide use for detecting methylation changes. Methylation-sensitive MLPA allows simple, rapid, accurate and economic screening of dosage imbalances and imprinting defects in this region, providing detailed information on the parental origin and the extent of the rearrangement, and appears thus as a method of choice to screen chromosome 15 abnormalities in patients with ASD.

\section{Acknowledgments}

We thank the families who participated in this research and the members of the Paris Autism Research International Sibpair (PARIS) Study for patient ascertainment (Supplement 1). We also thank the DNA and cell bank of the INSERM U679 (Hôpital Pitié-Salpêtrière) and the Centre d'Investigations CliniquesHôpital Robert Debré for processing the samples from the French families. This research was supported by Fondation de France, INSERM, Fondation pour la Recherche Médicale, Fondation France Télécom, Cure Autism Now, Assistance Publique-Hôpitaux de Paris, and the Swedish Science Council.

\section{Financial Disclosures}

The authors report no biomedical financial interests or potential conflicts of interests. 


\section{References}

1. Chakrabarti S, Fombonne E (2005): Pervasive developmental disorders in preschool children: confirmation of high prevalence. Am J Psychiatry 162:1133-41.

2. Abrahams BS, Geschwind DH (2008): Advances in autism genetics: on the threshold of a new neurobiology. Nat Rev Genet 9:341-55.

3. Kielinen M, Rantala H, Timonen E, Linna SL, Moilanen I (2004): Associated medical disorders and disabilities in children with autistic disorder: a population-based study. Autism 8:49-60.

4. Wassink TH, Piven J, Patil SR (2001): Chromosomal abnormalities in a clinic sample of individuals with autistic disorder. Psychiatr Genet 11:57-63.

5. Autism Genome Project Consortium (2007): Mapping autism risk loci using genetic linkage and chromosomal rearrangements. Nat Genet 39:319-28.

6. Sebat J, Lakshmi B, Malhotra D, Troge J, Lese-Martin C, Walsh T, et al. (2007): Strong association of de novo copy number mutations with autism. Science 316:445-9.

7. Marshall CR, Noor A, Vincent JB, Lionel AC, Feuk L, Skaug J, et al. (2008): Structural variation of chromosomes in autism spectrum disorder. Am J Hum Genet 82:477-88.

8. Vorstman JA, Staal WG, van Daalen E, van Engeland H, Hochstenbach PF, Franke L (2006): Identification of novel autism candidate regions through analysis of reported cytogenetic abnormalities associated with autism. Mol Psychiatry 11:1, 18-28.

9. Martinsson T, Johannesson T, Vujic M, Sjostedt A, Steffenburg S, Gillberg C, et al. (1996): Maternal origin of inv dup(15) chromosomes in infantile autism. Eur Child Adolesc Psychiatry 5:185-92.

10. Schroer RJ, Phelan MC, Michaelis RC, Crawford EC, Skinner SA, Cuccaro M, et al. (1998): Autism and maternally derived aberrations of chromosome 15q. Am J Med Genet 76:327-36.

11. Webb T, Hardy CA, King M, Watkiss E, Mitchell C, Cole T (1998): A clinical, cytogenetic and molecular study of ten probands with supernumerary inv dup (15) marker chromosomes. Clin Genet $53: 34-43$.

12. Wolpert CM, Menold MM, Bass MP, Qumsiyeh MB, Donnelly SL, Ravan SA, et al. (2000): Three probands with autistic disorder and isodicentric chromosome 15. Am J Med Genet 96:365-72.

13. Sahoo T, Shaw CA, Young AS, Whitehouse NL, Schroer RJ, Stevenson RE, et al. (2005): Arraybased comparative genomic hybridization analysis of recurrent chromosome $15 \mathrm{q}$ rearrangements. $\mathrm{Am}$ J Med Genet A 139:106-13.

14. Wang NJ, Liu D, Parokonny AS, Schanen NC (2004): High-resolution molecular characterization of 15q11-q13 rearrangements by array comparative genomic hybridization (array $\mathrm{CGH}$ ) with detection of gene dosage. Am J Hum Genet 75:267-81.

15. Cook EH, Jr., Lindgren V, Leventhal BL, Courchesne R, Lincoln A, Shulman C, et al. (1997): Autism or atypical autism in maternally but not paternally derived proximal $15 \mathrm{q}$ duplication. Am $J$ Hum Genet 60:928-34. 
16. Bolton PF, Dennis NR, Browne CE, Thomas NS, Veltman MW, Thompson RJ, et al. (2001): The phenotypic manifestations of interstitial duplications of proximal $15 \mathrm{q}$ with special reference to the autistic spectrum disorders. Am J Med Genet 105:675-85.

17. Thomas JA, Johnson J, Peterson Kraai TL, Wilson R, Tartaglia N, LeRoux J, et al. (2003): Genetic and clinical characterization of patients with an interstitial duplication 15q11-q13, emphasizing behavioral phenotype and response to treatment. Am J Med Genet A 119:111-20.

18. Browne CE, Dennis NR, Maher E, Long FL, Nicholson JC, Sillibourne J, et al. (1997): Inherited interstitial duplications of proximal 15q: genotype-phenotype correlations. Am J Hum Genet 61:1342-52.

19. Trillingsgaard A, Østergaard J (2004): Autism in Angelman syndrome: an exploration of comorbidity. Autism 8:163-74.

20. Sahoo T, Peters SU, Madduri NS, Glaze DG, German JR, Bird LM, et al. (2006): Microarray based comparative genomic hybridization testing in deletion bearing patients with Angelman syndrome: genotype-phenotype correlations. J Med Genet 43:512-6.

21. Bonati MT, Russo S, Finelli P, Valsecchi MR, Cogliati F, Cavalleri F, et al. (2007): Evaluation of autism traits in Angelman syndrome: a resource to unfold autism genes. Neurogenetics 8:169-78.

22. Pujana MA, Nadal M, Guitart M, Armengol L, Gratacos M, Estivill X (2002): Human chromosome 15q11-q14 regions of rearrangements contain clusters of LCR15 duplicons. Eur J Hum Genet 10:2635.

23. Lee JA, Lupski JR (2006): Genomic rearrangements and gene copy-number alterations as a cause of nervous system disorders. Neuron 52:103-21.

24. Cook EH, Jr., Courchesne RY, Cox NJ, Lord C, Gonen D, Guter SJ, et al. (1998): Linkagedisequilibrium mapping of autistic disorder, with 15q11-13 markers. Am J Hum Genet 62:1077-83.

25. Nygren AO, Ameziane N, Duarte HM, Vijzelaar RN, Waisfisz Q, Hess CJ, et al. (2005): Methylation-specific MLPA (MS-MLPA): simultaneous detection of CpG methylation and copy number changes of up to 40 sequences. Nucleic Acids Res 33:e128.

26. Veenstra-Vanderweele J, Christian SL, Cook EH, Jr. (2004): Autism as a paradigmatic complex genetic disorder. Annu Rev Genomics Hum Genet 5:379-405.

27. Schanen NC (2006): Epigenetics of autism spectrum disorders. Hum Mol Genet 15 Spec No 2:R13850.

28. Lord C, Rutter M, Le Couteur A (1994): Autism Diagnostic Interview-Revised: a revised version of a diagnostic interview for caregivers of individuals with possible pervasive developmental disorders. $J$ Autism Dev Disord 24:659-85.

29. Gillberg C, Gillberg C, Rastam M, Wentz E (2001): The Asperger Syndrome (and high-functioning autism) Diagnostic Interview (ASDI): a preliminary study of a new structured clinical interview. Autism 5:57-66. 
30. Blennow E, Bui TH, Kristoffersson U, Vujic M, Anneren G, Holmberg E, et al. (1994): Swedish survey on extra structurally abnormal chromosomes in 39105 consecutive prenatal diagnoses: prevalence and characterization by fluorescence in situ hybridization. Prenat Diagn 14:1019-28.

31. Huang B, Crolla JA, Christian SL, Wolf-Ledbetter ME, Macha ME, Papenhausen PN, et al. (1997): Refined molecular characterization of the breakpoints in small inv dup(15) chromosomes. Hum Genet 99:11-7.

32. Battaglia A (2005): The inv dup(15) or idic(15) syndrome: a clinically recognisable neurogenetic disorder. Brain Dev 27:365-9.

33. Roberts SE, Maggouta F, Thomas NS, Jacobs PA, Crolla JA (2003): Molecular and fluorescence in situ hybridization characterization of the breakpoints in 46 large supernumerary marker 15 chromosomes reveals an unexpected level of complexity. Am J Hum Genet 73:1061-72.

34. Dennis NR, Veltman MW, Thompson R, Craig E, Bolton PF, Thomas NS (2006): Clinical findings in 33 subjects with large supernumerary marker(15) chromosomes and 3 subjects with triplication of 15q11-q13. Am J Med Genet A 140:434-41.

35. Boyar FZ, Whitney MM, Lossie AC, Gray BA, Keller KL, Stalker HJ, et al. (2001): A family with a grand-maternally derived interstitial duplication of proximal 15q. Clin Genet 60:421-30.

36. Thomas NS, Roberts SE, Browne CE (2003): Estimate of the prevalence of chromosome 15q11-q13 duplications. Am J Med Genet A 120A:596-8.

37. Bolton PF, Veltman MW, Weisblatt E, Holmes JR, Thomas NS, Youings SA, et al. (2004): Chromosome 15q11-13 abnormalities and other medical conditions in individuals with autism spectrum disorders. Psychiatr Genet 14:131-7.

38. Engelen JJ, Loots WJ, Albrechts JC, Schrander-Stumpel CT, Dirckx R, Smeets HJ, et al. (1999): Duplication within chromosome region 15q11-q13 in a patient with similarities to Prader-Willi syndrome confirmed by region-specific and band-specific FISH. Genet Couns 10:123-32.

39. Mohandas TK, Park JP, Spellman RA, Filiano JJ, Mamourian AC, Hawk AB, et al. (1999): Paternally derived de novo interstitial duplication of proximal $15 \mathrm{q}$ in a patient with developmental delay. Am J Med Genet 82:294-300.

40. Mao R, Jalal SM, Snow K, Michels VV, Szabo SM, Babovic-Vuksanovic D (2000): Characteristics of two cases with dup(15)(q11.2-q12): one of maternal and one of paternal origin. Genet Med 2:1315.

41. Smith M, Hanouni M, Spence MA, Gargus JJ, Lerner MA (2004): Paternally derived 15q12-q13 duplication associated with autism spectrum disorder. Presented at the annual meeting of The American Society for Human Genetics, October 26-30, 2004, Toronto, Canada.

42. Cassidy S, Conroy J, Becker L, Schwartz S (1996): Paternal triplication of 15q11-q13 in a hypotonic, developmentally delayed child without Prader-Willi or Angelman syndrome. Abstracts for the Ninth Annual Scientific Conference of the Prader-Willi Syndrome (PWS) Association. Am J Med Genet 62:206-7. 
43. Ungaro P, Christian SL, Fantes JA, Mutirangura A, Black S, Reynolds J, et al. (2001): Molecular characterisation of four cases of intrachromosomal triplication of chromosome 15q11-q14. J Med Genet 38:26-34.

44. Dimitropoulos A, Schultz RT (2007): Autistic-like symptomatology in Prader-Willi syndrome: a review of recent findings. Curr Psychiatry Rep 9:159-64.

45. Steffenburg S, Gillberg CL, Steffenburg U, Kyllerman M (1996): Autism in Angelman syndrome: a population-based study. Pediatr Neurol 14:131-6.

46. Williams CA, Beaudet AL, Clayton-Smith J, Knoll JH, Kyllerman M, Laan LA, et al. (2006): Angelman syndrome 2005: updated consensus for diagnostic criteria. Am J Med Genet A 140:413-8.

47. Murthy SK, Nygren AO, El Shakankiry HM, Schouten JP, Al Khayat AI, Ridha A, et al. (2007): Detection of a novel familial deletion of four genes between BP1 and BP2 of the PraderWilli/Angelman syndrome critical region by oligo-array CGH in a child with neurological disorder and speech impairment. Cytogenet Genome Res 116:135-40.

48. Seleme MC, Shaikh TH, Lincicum M, Sathanoori M, Surti U, Hakonarson H, et al. (2007): Chromosome 15q11.2 copy number variants (CNV): population frequency and clinical implications. Presented at the annual meeting of The American Society of Human Genetics, October 23-27, 2007, San Diego, California.

49. Butler MG, Bittel DC, Kibiryeva N, Talebizadeh Z, Thompson T (2004): Behavioral differences among subjects with Prader-Willi syndrome and type I or type II deletion and maternal disomy. Pediatrics 113:565-73.

50. Bittel DC, Kibiryeva N, Butler MG (2006): Expression of 4 genes between chromosome 15 breakpoints 1 and 2 and behavioral outcomes in Prader-Willi syndrome. Pediatrics 118:e1276-83.

51. Stefansson H, Rujescu D, Cichon S, Pietilainen OP, Ingason A, Steinberg S, et al. (2008): Large recurrent microdeletions associated with schizophrenia. Nature 455:232-6.

52. Nishimura Y, Martin CL, Vazquez-Lopez A, Spence SJ, Alvarez-Retuerto AI, Sigman M, et al. (2007): Genome-wide expression profiling of lymphoblastoid cell lines distinguishes different forms of autism and reveals shared pathways. Hum Mol Genet 16:1682-98.

53. Roberts SE, Dennis NR, Browne CE, Willatt L, Woods G, Cross I, et al. (2002): Characterisation of interstitial duplications and triplications of chromosome 15q11-q13. Hum Genet 110:227-34.

54. Veltman MW, Thompson RJ, Craig EE, Dennis NR, Roberts SE, Moore V, et al. (2005): A paternally inherited duplication in the Prader-Willi/Angelman syndrome critical region: a case and family study. J Autism Dev Disord 35:117-27. 
Table 1. Clinical features of patients with rearrangements of the $15 \mathrm{q} 11-\mathrm{q} 13$ region

\begin{tabular}{|c|c|c|c|c|c|c|c|c|c|}
\hline Patient & Rearrangement & $\begin{array}{c}\text { Origin } \\
\text { (chromosome) }\end{array}$ & Gender & $\begin{array}{l}\text { Age at last } \\
\text { evaluation }\end{array}$ & ASD & $\begin{array}{c}\text { Developmental } \\
\text { delay }\end{array}$ & Language & Epilepsy & Other features \\
\hline \multicolumn{10}{|c|}{ Pathogenic rearrangements } \\
\hline Patient 1 & $\begin{array}{l}\operatorname{idic}(15) \\
\text { (pter-15q13.3, distal BP } \\
\text { between BP4/BP5) }\end{array}$ & de novo (maternal) & $\mathrm{F}$ & $30 \mathrm{y}$ & Autism & Severe MR & No language & $\begin{array}{l}\text { Absence seizures, } \\
\text { resistant to } \\
\text { treatment } \\
\text { (onset } 13 \mathrm{y})\end{array}$ & $\begin{array}{l}\text { Feeding difficulties, psychomotor delay, } \\
\text { dysmorphic features (large bulbous nose, } \\
\text { dental malposition, prominent jaw), short } \\
\text { stature }\end{array}$ \\
\hline Patient 2 & $\begin{array}{l}\text { interstitial duplication } \\
\text { (BP2-BP3) }\end{array}$ & paternal & M & $6 y$ & Autism & Moderate MR & $\begin{array}{l}\text { Speech delay, } \\
\text { no phrases }\end{array}$ & No & $\begin{array}{l}\text { Frequent otitis, mastication/swallowing } \\
\text { difficulties, no dysmorphic features }\end{array}$ \\
\hline Patient 3 & $\begin{array}{l}\text { deletion BP2-BP3 } \\
\text { (Class I) }\end{array}$ & de novo (maternal) & M & $24 \mathrm{y}$ & Autism & Severe MR & No language & No & $\begin{array}{l}\text { Sleep difficulties, delayed motor development, } \\
\text { gait difficulties and inappropriate laughter } \\
\text { during infancy, unilateral renal hypoplasia, } \\
\text { strabismus, tongue protrusion, no } \\
\text { dysmorphism, normal head circumference, } \\
\text { normal brain CT, normal EEG }\end{array}$ \\
\hline Patient 4 & $\begin{array}{l}\text { paternal uniparental } \\
\text { disomy }\end{array}$ & de novo (paternal) & M & $18 \mathrm{y}$ & Autism & Severe MR & $\begin{array}{l}\text { Limited language, } \\
\text { no phrases }\end{array}$ & $\begin{array}{l}\text { Absence } \\
\text { seizures since } \\
\text { early childhood; } \\
\text { seizure-free at } \\
\text { present }\end{array}$ & $\begin{array}{l}\text { Normal motor development, hyperactivity, } \\
\text { aggressiveness, sleep difficulties, minor } \\
\text { dysmorphic features (slightly bulbous nose, } \\
\text { dysplastic ears, widely spaced teeth), } \\
\text { tapering fingers, hyperextension of finger } \\
\text { joints, bilateral genu valgum, pyramidal } \\
\text { syndrome, slightly spastic gait, no inappro- } \\
\text { priate laughter, normal head circumference }\end{array}$ \\
\hline \multicolumn{10}{|c|}{ Copy number variants likely non pathogenic } \\
\hline Patient 5 & deletion BP1-BP2 & paternal & M & $5 \mathrm{y}$ & Autism & Severe MR & No language & $\begin{array}{l}\text { No (but abnormal } \\
\text { EEG) }\end{array}$ & $\begin{array}{l}\text { Hypotonia, motor delay, frequent respiratory } \\
\text { infections during infancy, macroce- } \\
\text { phaly, retrognathia, normal brain MRI }\end{array}$ \\
\hline Patient 6 & deletion BP1-BP2 & maternal & $\mathrm{F}$ & $13 \mathrm{y}$ & Autism & Normal IQ & No speech delay & No & $\begin{array}{l}\text { Developmental coordination disorder, } \\
\text { depression. The mother, who also carries the } \\
\text { deletion, has panic disorder and depression }\end{array}$ \\
\hline Patient 7 & deletion BP1-BP2 & paternal & $\mathrm{F}$ & $9 y$ & Autism & Normal IQ & No speech delay & No & $\begin{array}{l}\text { ADHD combined type. Two older sisters also } \\
\text { carry the deletion, one with ADHD and the other } \\
\text { with dyslexia, while the younger healthy brother } \\
\text { did not inherit the deletion. }\end{array}$ \\
\hline Patient 8 & duplication BP1-BP2 & maternal & M & $5 \mathrm{y}$ & Autism & Severe MR & Functional language & Yes (onset $9 \mathrm{~m}$ ) & Normal brain MRI \\
\hline Patient 9 & duplication BP1-BP2 & paternal & M & $15 \mathrm{y}$ & Autism & Severe MR & No language & $\begin{array}{l}1 \text { absence } \\
\text { seizure at } 11 \mathrm{y}\end{array}$ & $\begin{array}{l}\text { Neonatal overgrowth, macrocephaly and } \\
\text { increased height persist, long narrow hands } \\
\text { and feet }\end{array}$ \\
\hline Patient 10 & deletion ex $1 U B E 3 A$ & paternal & M & $6 y$ & Autism & Mild MR & $\begin{array}{l}\text { Severe language } \\
\text { impairment }\end{array}$ & No & $\begin{array}{l}\text { No dysmorphic features, normal neurological } \\
\text { exam }\end{array}$ \\
\hline
\end{tabular}


Table 2. Patients with paternally-derived interstitial duplications or triplications of chromosome 15q11q13 with an abnormal phenotype reported in the literature

\begin{tabular}{|c|c|c|c|c|}
\hline Study & Rearrangement & Sex & Age & Clinical characteristics \\
\hline $\begin{array}{l}\text { Mohandas et al., } 1999 \\
\text { (39) }\end{array}$ & $\begin{array}{l}\text { duplication } \\
\text { (at least BP2-BP3) }\end{array}$ & M & $2 \mathrm{y}, 4 \mathrm{mo}$ & $\begin{array}{l}\text { developmental delay, absent speech, partial } \\
\text { agenesis of the corpus callosum and heterotopic gray } \\
\text { matter in the right hemisphere; no dysmorphic features }\end{array}$ \\
\hline $\begin{array}{l}\text { Engelen et al., } 1999 \\
(38)\end{array}$ & $\begin{array}{l}\text { duplication } \\
\text { (at least BP2-BP3) }\end{array}$ & M & $12 \mathrm{y}$ & $\begin{array}{l}\text { features similar to Prader-Willi syndrome, including } \\
\text { developmental delay, obesity starting during the first year } \\
\text { of life, mild mental retardation, excessive eating, } \\
\text { skin picking, minor dysmorphic features (high forehead, } \\
\text { upslanting palpebral fissures), myopia, and small hands }\end{array}$ \\
\hline $\begin{array}{l}\text { Mao et al., } 2000 \\
(40)\end{array}$ & $\begin{array}{l}\text { duplication } \\
\text { (at least BP2-BP3) }\end{array}$ & M & $16 \mathrm{y}$ & $\begin{array}{l}\text { developmental and speech delay, behavioral problems } \\
\text { (mood liability, social immaturity), uncontrolled appetite, } \\
\text { food stealing, self-injurious behavior, depression and } \\
\text { anxiety, low average IQ, short stature, obesity, no } \\
\text { dysmorphic features }\end{array}$ \\
\hline \multirow[t]{2}{*}{$\begin{array}{l}\text { Roberts et al., 2002, } \\
\text { Bolton et al., 2004, } \\
\text { Veltman et al., } 2005 \\
(37,53,54)\end{array}$} & duplication BP1-BP3 & $\mathrm{F}$ & $5 \mathrm{y}$ & $\begin{array}{l}\text { proband: motor and speech delay delay, PDD-NOS, } \\
\text { borderline mental retardation, clumsy and uncoordinated, } \\
\text { stiff gait, mild hypotonia, joint laxity, slight down- } \\
\text { slanting palpebral fissures }\end{array}$ \\
\hline & duplication BP1-BP3 & $\mathrm{F}$ & $8 \mathrm{y}$ & $\begin{array}{l}\text { older sister: language and speech delay, developmental } \\
\text { motor coordination disorder, oppositional defiant behavior, } \\
\text { encopresis, autistic behavior when younger but no ASD } \\
\text { at } 8 \mathrm{y} \text {, low average IQ; clumsy, mild hypotonia, joint laxity* }\end{array}$ \\
\hline $\begin{array}{l}\text { Smith et al., } 2004 \\
(41)\end{array}$ & $\begin{array}{l}\text { duplication } \\
\text { BP2-BP3 }\end{array}$ & $\mathrm{F}$ & $17 \mathrm{y}$ & $\begin{array}{l}\text { hypotonia, development and speech delay, autism, } \\
\text { dyscalculia, short stature, minimal dysmorphism and motor } \\
\text { coordination problems; normal IQ }\end{array}$ \\
\hline $\begin{array}{l}\text { Cassidy et al., } 1996 \\
\text { (42) }\end{array}$ & $\begin{array}{l}\text { triplication } \\
\text { BP2-BP3 } \\
\text { (BP1-2 not studied) } \\
\text { (BP3-4 normal) }\end{array}$ & $\mathrm{F}$ & $6 \mathrm{y}$ & $\begin{array}{l}\text { neonatal hypotonia, difficulty feeding, motor and } \\
\text { speech delay (words } 2.5 \mathrm{y} \text {, phrases } 6 \mathrm{y} \text { ), violent and } \\
\text { repetitive behavior, high pain tolerance, short stature, } \\
\text { wide mouth, normal neurological exam }\end{array}$ \\
\hline $\begin{array}{l}\text { Ungaro et al., } 2001 \\
\text { (43) }\end{array}$ & $\begin{array}{l}\text { triplication } \\
\text { BP1-BP4 }\end{array}$ & $\mathrm{F}$ & $12 \mathrm{y}$ & $\begin{array}{l}\text { features similar to Prader-Willi syndrome, including } \\
\text { mild mental retardation, cleft palate, obesity, compulsive } \\
\text { eating, small hands and feet, and short stature }\end{array}$ \\
\hline
\end{tabular}

All rearrangements included the Prader-Willi syndrome/Angelman syndrome critical region. All duplications/triplications were characterized molecularly and parental transmission was assessed with methylation studies, except Engelen et al. (38) who determined parental origin based on cytogenetic polymorphisms, and Smith et al. (41), who used microsatellite analysis. In addition, Engelen et al. (38) observed the duplication with FISH but microsatellite analysis showed no duplication and the methylation pattern was normal, thus making this case questionable.

*Another sibling, who did not carry the duplication, also had mild hypotonia and a history of marked speech delay and articulatory dyspraxia, while the mother had delayed speech and troubles with reading and writing in school.

Abbreviations: ASD, autism spectrum disorder; BP, breakpoint, PDD-NOS, pervasive developmental disorder not otherwise specified 


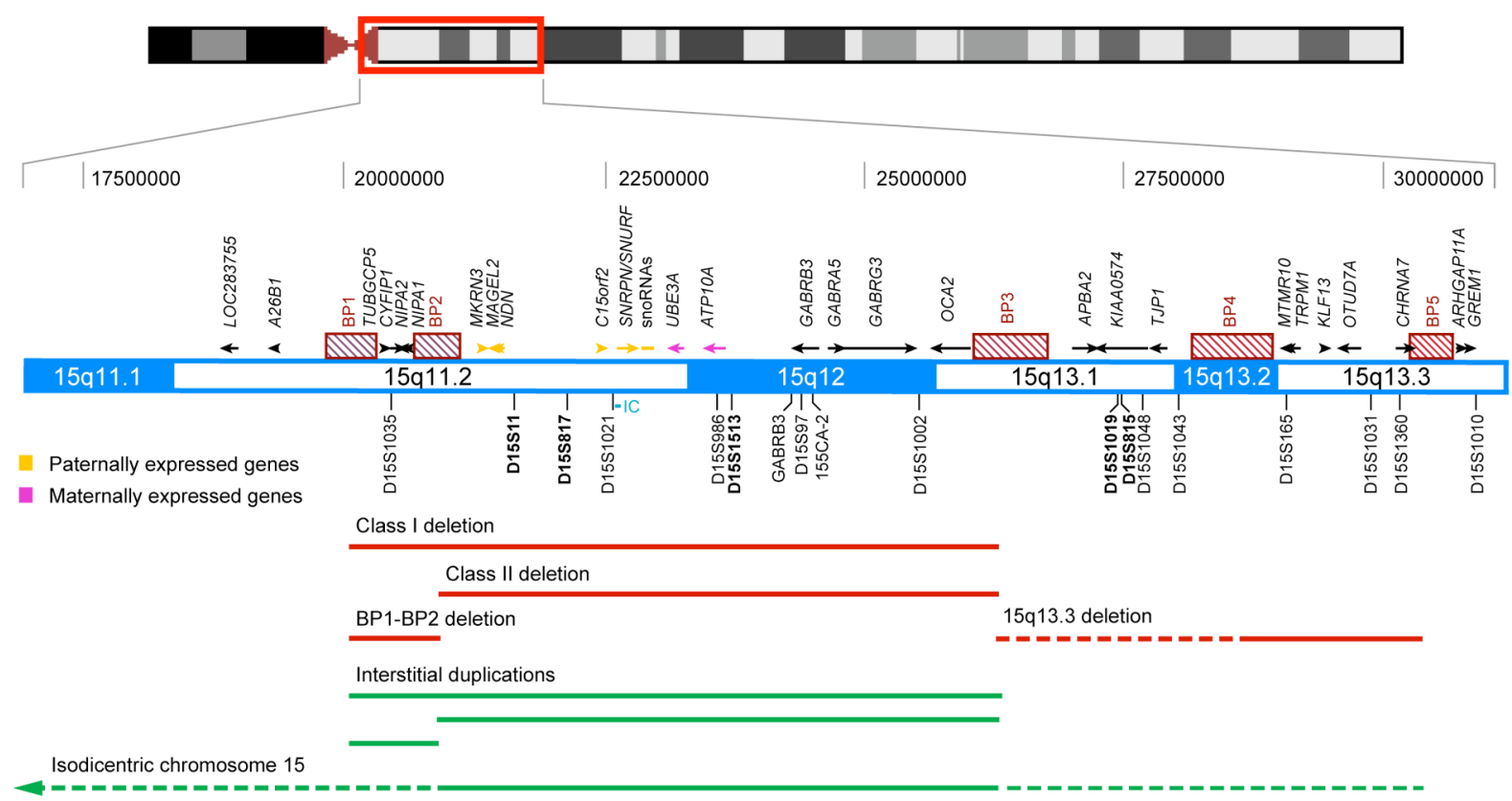

Figure 1. Map of chromosome 15 showing the Prader-Willi/Angelman syndrome critical region. Genes are shown above the map and microsatellites below. The five microsatellite markers used in the quantitative analysis are indicated in bold. Paternally and maternally expressed genes are indicated in yellow and pink, respectively. The recurrent breakpoints (BP) are indicated as purple boxes. The imprinting center (IC), located in the $5^{\prime}$ untranslated region of $S N R P N$, is indicated in green. The horizontal red bars indicate the regions deleted in Angelman and Prader-Willi syndromes (class I and class II deletions), as well as the recently described copy number variant between BP1 and BP2 and the $15 \mathrm{q} 13.3$ microdeletion syndrome. The horizontal green bars indicate the regions involved in typical interstitial duplications and supernumerary isodicentric chromosome 15 . The critical region for Prader-Willi, Angelman and 15q11-q13 duplication syndromes lies between BP2 and BP3. The distance (expressed in $\mathrm{Mb}$ from pter) is shown at the top of the map. 

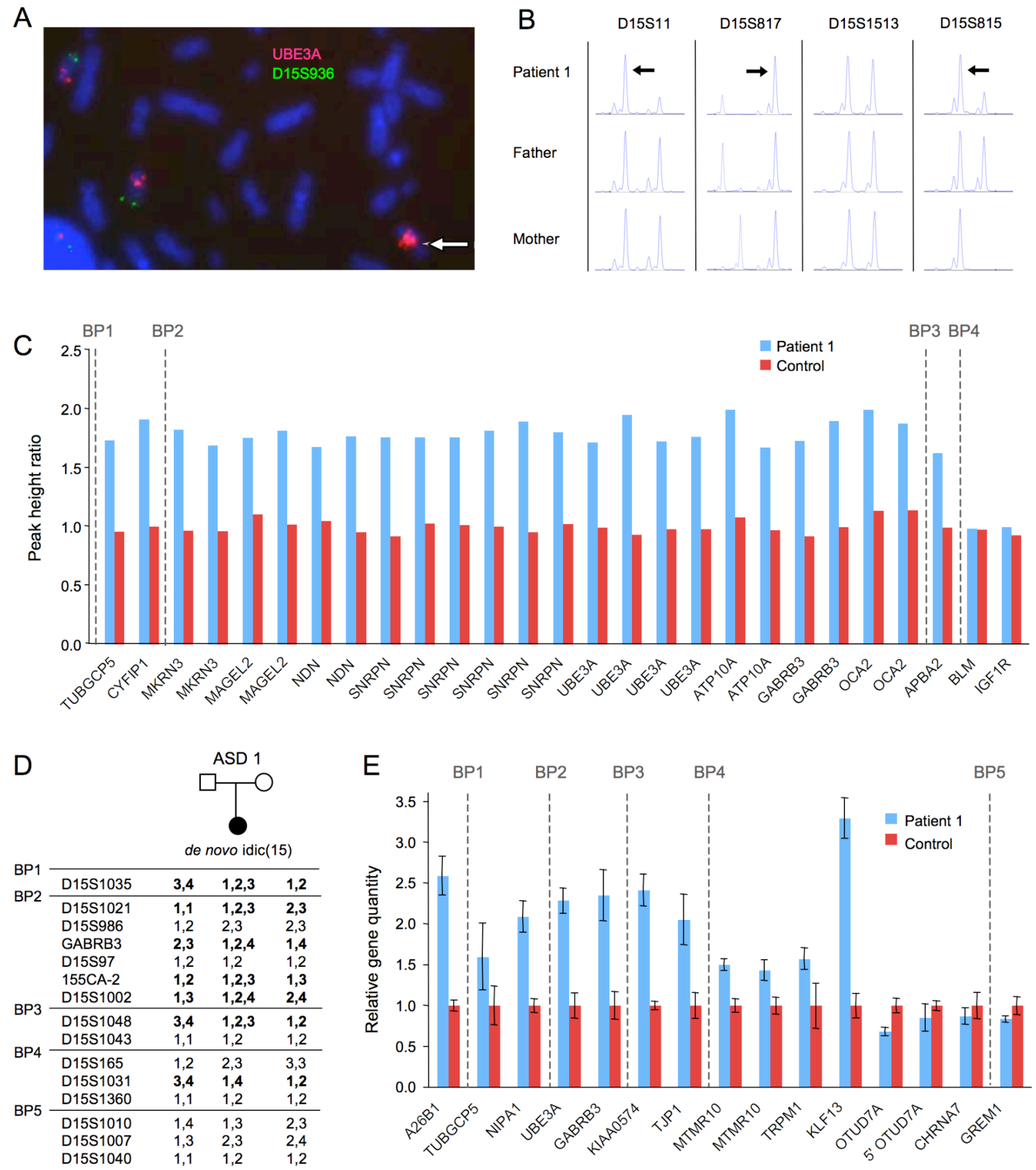

Figure 2. Supernumerary isodicentric chromosome 15 in Patient 1. A. Metaphase FISH of lymphoblastoid cell lines from Patient 1 using probes UBE3A (red) for the region of interest and D15S936 (green) as a control probe in $15 \mathrm{q} 26.3$ showed two normal signals on chromosomes 15 as well as additional hybridization spots of the duplicated 15q11-q13 region (red) on a supernumerary chromosome (arrow). B. Quantitative microsatellite analyses showed increased dosage of D15S11, D15S817 and D15S815 in the proband, but not in her parents. C. MPLA confirmed increased copy number of all the probes in the 15q11-q13 region between BP1 and BP4 (from TUBGCP5 to APBA2), and normal dosage of BLM and IGF1, located at the distal end of the chromosome, at 15q26. The peak heights above 1.5 are consistent with tetrasomy of the region. D. Genotyping of microsatellites in the 15q11-q13 region revealed three alleles for informative markers between BP1 and BP4, with one allele of paternal origin and two of maternal origin. The presence of one informative microsatellite, D15S1031, with a single maternal allele indicates that the breakpoint lies proximal to this marker. E. Genomic qPCR showed a transition from increased copy number to normal dosage between KLF13 and OTUD7A, indicating that the distal breakpoint lies between BP4 and BP5. 


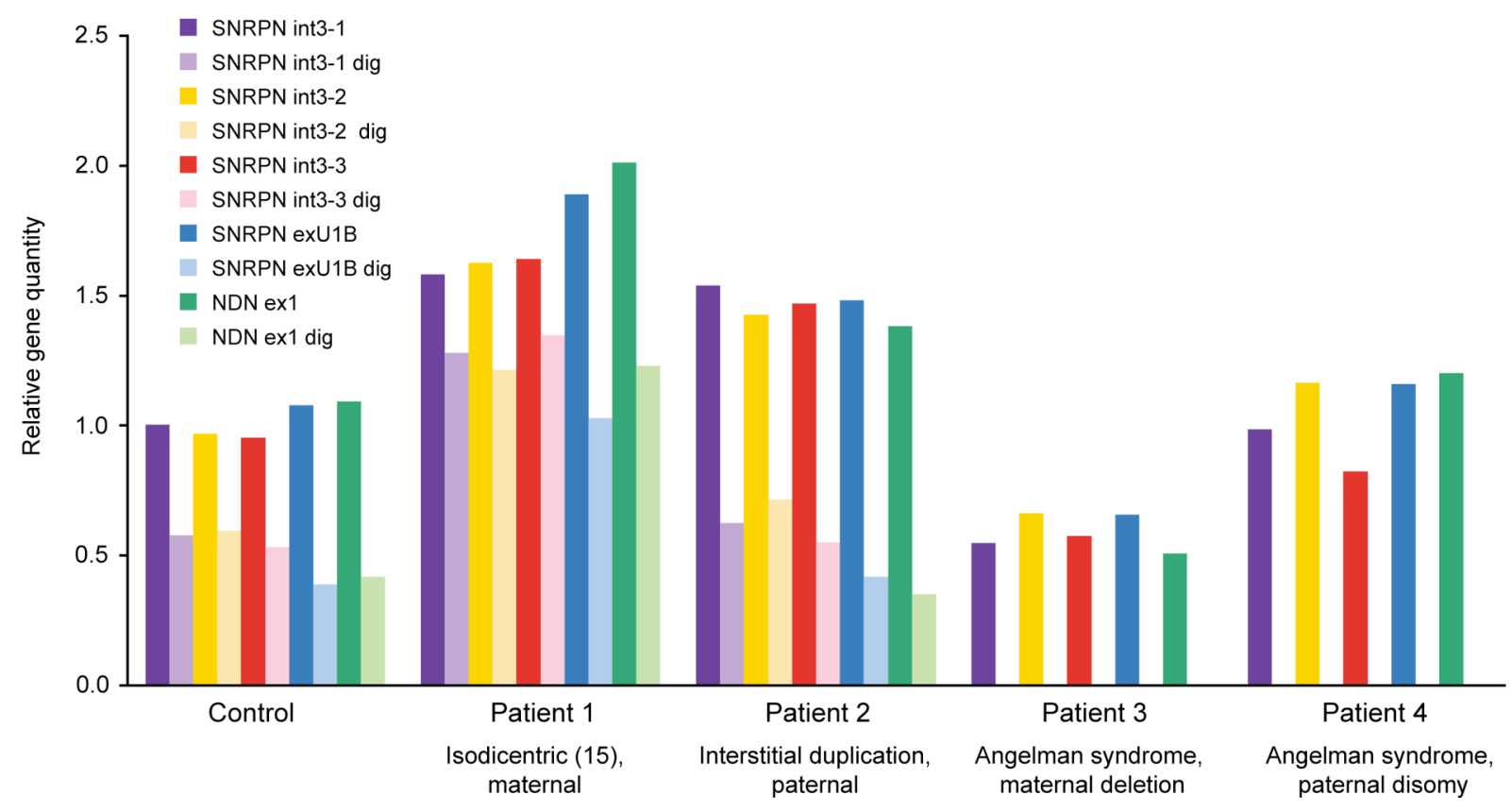

Figure 3. Methylation-sensitive MLPA of the chromosome 15q region. Histograms show the dosage of probes located in the $S N R P N$ and $N D N$ promoter regions in undigested and digested DNA. In undigested DNA, both the maternal and paternal copies of the genes are visible. Because SNRPN and $N D N$ are paternally imprinted, after digestion with the methylation-sensitive enzyme HhaI only the maternally methylated DNA sequences are amplified, indicated by the light-colored bars. In a normal subject (control), a 50\% reduction in peak height is observed after digestion. Patient 1 , who has an isodicentric chromosome 15, shows 4 copies of the probes in the PWS/AS region, and a twofold increase in peak height of methylated DNA sequences, corresponding to a maternal origin of the extra chromosome. Patient 2 shows no increase in amplification of methylated DNA sequences after digestion, as expected with a duplication of paternal origin. Patient 3, with an Angelman syndrome resulting from a maternal deletion of chromosome 15q11-q13, shows a 50\% reduction in peak height of probes in the PWS/AS region, and absent methylated DNA peaks after digestion. Patient 4, with Angelman syndrome resulting from a paternal uniparental disomy, shows normal peak heights before digestion with HhaI, and an absence of methylated DNA peaks afterwards, indicating the presence of two paternal chromosomes. 


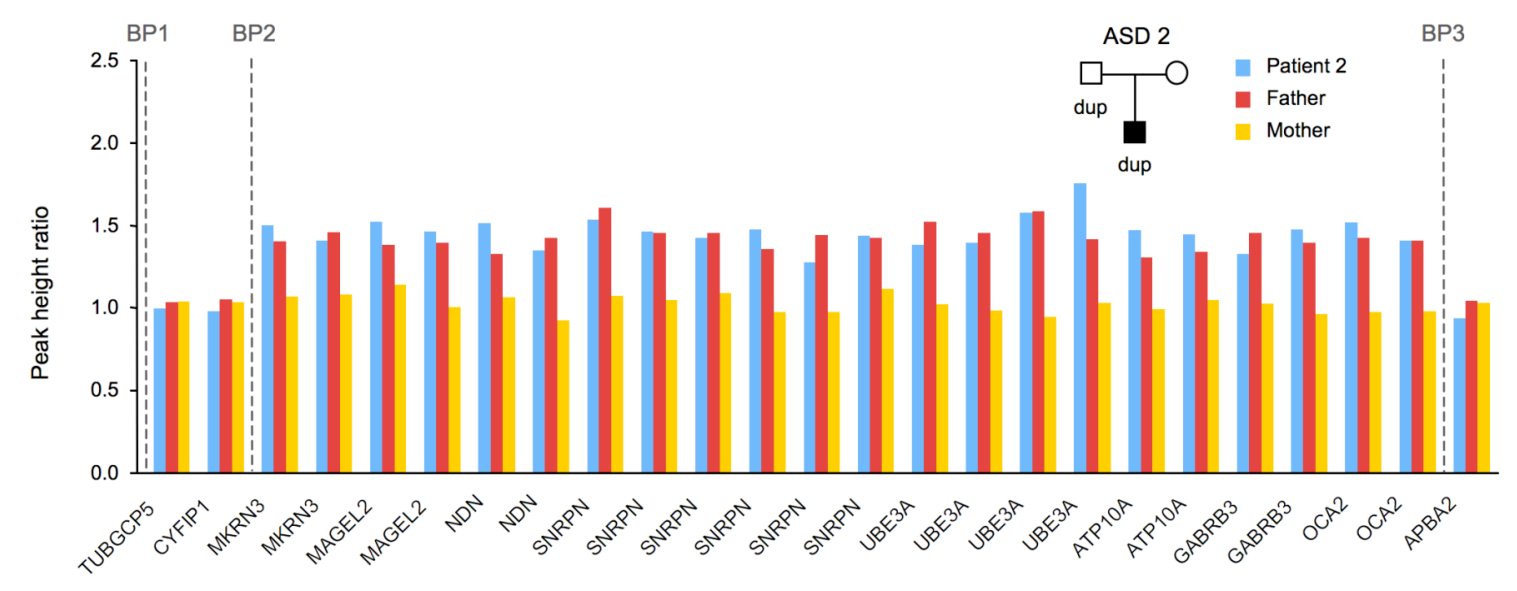

Figure 4. Paternally inherited interstitial duplication of chromosome 15 in family ASD 2. MPLA showed increased gene dosage of all the genes from $M K R N 3$ to $O C A 2$, between BP2 and BP3, while the genes before BP2 (TUBGCP5 and CYFIP1) and after BP3 (APBA2) showed normal dosage. 
A

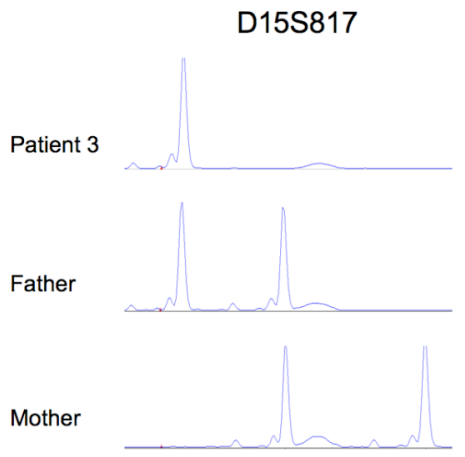

B

$\mathrm{C}$

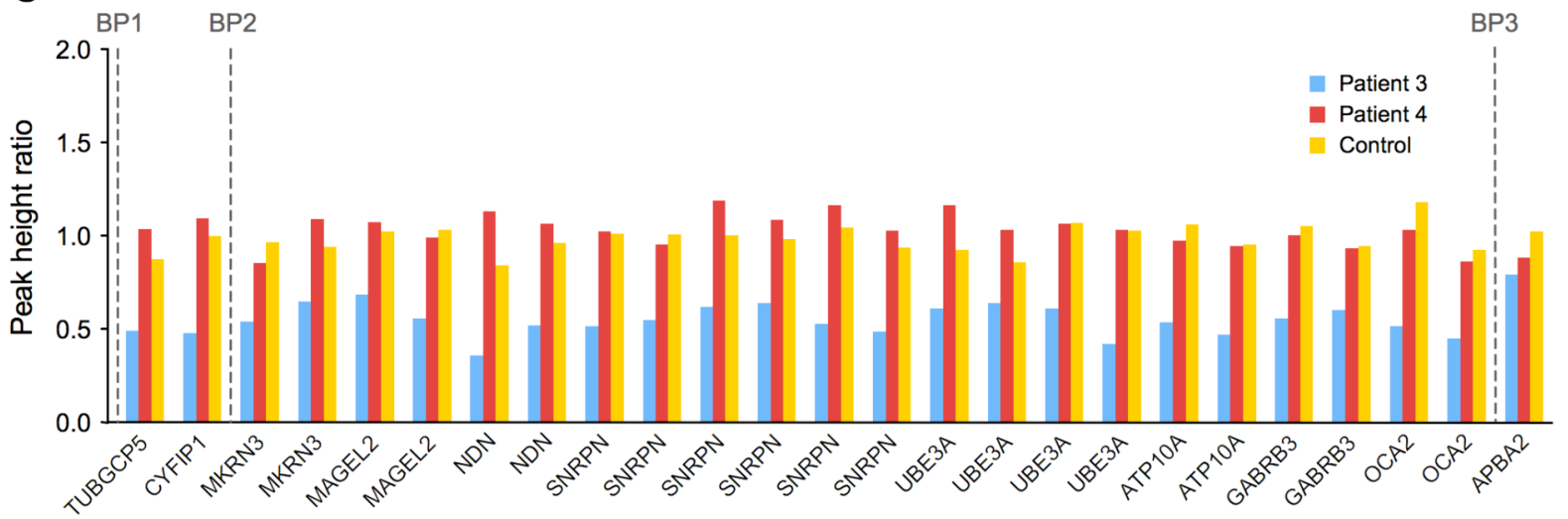

Figure 5. Two patients with ASD and Angelman syndrome, one secondary to a maternal deletion (family ASD 3) and the other to a paternal uniparental disomy (family ASD 4). A. Microsatellites D15S817 and D15S1019 show loss of heterozygosity, with apparently only one allele inherited from the father in both probands. B. Genotyping of five microsatellites in the 15q11-q13 region confirmed the presence of only one allele inherited from the father in Patient 3, indicating a maternal deletion. Patient 4 showed two alleles inherited from the father, indicating a paternal uniparental disomy. C. MPLA showed normal gene dosage in Patient 4, as expected in an uniparental isodisomy, and a 50\% reduction in probes ranging from $T U B G C P 5$ to $O C A 2$ in Patient 3 , showing a class I deletion of the $\mathrm{PWS} / \mathrm{AS}$ region. 